\title{
Educação a domicílio O mercado bate à sua porta
}

\section{Theresa Adrião* \\ Teise Garcia ${ }^{* *}$}

\begin{abstract}
Resumo: O artigo analisa a relação entre educação domiciliar (homeschooling e aulas particulares) e privatização da oferta da educação na etapa obrigatória. Busca identificar essa prática com a tendência de ampliação de políticas de escolha parental que podem aprofundar desigualdades educativas e subordinar a educação básica a interesses privados, para além daqueles expressos nos interesses das famílias. Caracterizamos a atuação do Grupo Pearson, que mantém um setor especificamente voltado para a educação doméstica.
\end{abstract}

Palavras-chave: Educação domiciliar. Escolha parental. Privatização. Tutorias. Pearson.

\section{Home Schooling}

The market knocks at its door

\begin{abstract}
The article analyzes the relationship between home education (homeschooling and private lessons) and the privatization of the provision of education in the obligatory stages. It seeks to identify this practice with the tendency to expand policies of parental choice that can deepen educational inequalities and subordinate basic education to private interests, in addition to those expressed in the interests of families. We characterize the performance of the
\end{abstract}

* Professora livre docente da Faculdade de Educação da UNICAMP, coordena o Grupo de Estudos e Pesquisas em Política Educacional (GREPPE)/Unicamp. É integrante da Associação Nacional de Financiamiento da Educação (Fineduca) e Coordena o Grupo de Trabalho 5 "Estado e Política Educacional" da ANPED. Campinas- SP- Brasil. E-mail: <theadriao@gmail.com>.

* Professora Doutora no departamento de Educação Informação e Comunicação da Universidade de São Paulo e coordenadora do Programa de Pós-Graduação em Educação da FFCLRP. Coordena também o Grupo de Estudos e Pesquisas em Política Educacional, Greppe-USP/RP e é vice-diretora estadual da Anpae SP. Ribeirão Preto, SP- Brasil. E-mail: <teiseg2@gmail.com>. 
Pearson Group, which maintains a sector specifically focused on domestic education.

Keywords: Home schooling. Parental choice. Privatization. Tutorials. Pearson.

\section{Educación a domicilio \\ El mercado llama a su puerta}

RESUMEN: El artículo analiza la relación entre la educación domiciliaria (homeschooling y clases particulares) y la privatización de la oferta de la educación en la etapa obligatoria. Buscamos identificar esta práctica con la tendencia a la ampliación de políticas de elección parental que pueden aumentar las desigualdades educativas y subordinar la educación básica a intereses privados, más allá de los expresados en los intereses de las familias. Caracterizamos la actuación del Grupo Pearson, que mantiene un sector específicamente orientado hacia la educación doméstica.

Palabras clave: Educación domiciliaria. Elección parental. Privatización. Tutorías. Pearson.

\section{Éducation à domicile \\ Le marché frappe à votre porte}

RÉSUMÉ: L'article analyse le rapport entre l'éducation à domicile (homeschooling et cours particuliers) et la privatisation de l'offre éducative au stade de scolarité obligatoire. Il cherche à identifier cette pratique avec la tendance à élargir les politiques de choix parental qui peuvent aggraver les inégalités éducatives et subordonner l'éducation de base à des intérêts privés, en plus de ceux exprimés par les familles. Nous avons ici analysé la prestation du Groupe Pearson qui maintient un secteur spécifiquement axé sur l'éducation à domicile.

Mots-clés: Éducation à domicile. Choix parental. Privatisation. Tutoriels. Pearson. 


\section{Introdução}

reflexão proposta neste artigo toma a opção pela substituição total ou parcial do
processo educativo em ambiente escolar por atividades educativas ofertadas
privadamente como uma das formas pelas quais se privatiza a oferta educacional. Essas opções educativas operacionalizam-se tanto pelo homeschooling (educação doméstica) propriamente dito, aquele ofertado pelos familiares ou grupos de famílias, quanto pelo contrato de profissionais ou empresas para a oferta de aulas particulares de modo complementar ou em substituição à educação escolar. A este conjunto de possibilidades denomina-se neste artigo educação a domicílio.

O pressuposto de que se trata de processo de privatização da educação escolar decorre de diálogo com inventário de publicações em Língua Inglesa que abordam o ensino domiciliar nessa perspectiva e indagam sobre a possibilidade de que estes tipos de escolhas parental aprofundem desigualdades educativas e subordinem a educação básica a interesses privados para além daqueles expressos nos interesses das famílias. Mais precisamente o texto considera a expansão deste tipo de oferta educativa como mais um segmento para expansão dos negócios educacionais.

Neste trabalho enfatiza-se este último aspecto por meio da apresentação e problematização de informações relativas à atuação de uma das maiores corporações mundiais com atuação na Educação: O Grupo Pearson.

As perspectivas educativas pautadas na escolha parental, que sugere tratar-se de ampliação de direitos individuais, representa também uma relevante forma de privatização da educação obrigatória. (APPLE, 2001, LEVIN, 2001). Sinteticamente, a escolha parental, viabilizada por subsídios públicos, operacionaliza-se pela adoção de mecanismos como bolsas de estudo ou vouchers para matrícula em escolas particulares; créditos fiscais reembolsáveis destinados a empresas ou a famílias e o estabelecimento de convênios ou contratos entre o poder público e escolas privadas (charter schools). Segundo o movimento de Advocacy National School Choice Week, a educação domiciliar (homeschooling) é outro mecanismo pelo qual se operacionaliza a escolha educativa. (ADRIÃO, 2015)

De acordo com a organização estadunidense pró-educação domiciliar, Home School Legal Defense Association (HSLDA), ${ }^{1} \mathrm{em}$ 2016, onze estados americanos autorizavam esse tipo de educação sem qualquer exigência ou acompanhamento por parte dos distritos escolares. ${ }^{2}$ A HSLDA tem, historicamente, se oposto ao repasse de recursos públicos, mesmo a famílias de baixa renda praticantes do homeshooling. Por outro lado, a organização não governamental Coalition for Responsible Home Education, criada por ex-alunos dessa modalidade educativa nos Estados Unidos, apregoa que o financiamento público para a prática não seria novidade e poderia ser instituído desde que fossem assegurados procedimentos de prestação de contas e avaliação. ${ }^{3}$ 
Se o financiamento público à prática do homeschooling nos USA é um tema polêmico naquele país e entre nós e a própria alternativa careça de autorização (BARBOSA, 2013), no Brasil cresce outra modalidade de educação a domicílio: as aulas particulares. Mesmo que essa modalidade educacional seja predominantemente custeada pelas famílias, as aulas particulares ou "explicações", como denominadas em Portugal. (COSTA, NETO MENDES, VENTURA, 2009), têm sido incorporadas a programas governamentais de "extensão de jornada escolar" e ofertadas por instituições privadas como escolas de idiomas.

Em síntese, para efeito da reflexão aqui desenvolvida, entende-se por educação a domicílio a substituição total da frequência à escola pela educação doméstica ou a complementação das atividades escolares por aulas particulares. Em ambos os casos assume-se como relevante o segmento de mercado criado quer pela comercialização de material didático dirigido às famílias que optam pela educação doméstica, quer pela criação de empresas para o atendimento educacional a domicílio que, neste caso, ofertam aulas particulares de disciplinas escolares específicas, serviços de acompanhamento de estudos ou ainda substituindo as próprias famílias na educação domiciliar.

O primeiro item do artigo apresenta resultados de mapeamento de publicações em Língua Inglesa relativas à escolha parental, disponíveis no Web of Science e publicadas no período de 1990 a 2014, condição que engloba a temática em diferentes países. Dialoga também com a produção discente brasileira disponível no Banco de Tese da Capes no mesmo período.

Na sequência, visando a compreender o mercado da educação a domicílio, caracteriza-se um grupo empresarial que, com vistas a ampliar o segmento de "edubusiness" (HILL, 2003; BALL, 2004) direciona sua atuação também para a educação doméstica. Para este fim, adota-se a pesquisa documental em fontes primárias e institucionais e em fontes secundárias.

Finaliza-se com considerações a respeito dessa forma de oferta educativa em relação às dimensões do direito à educação quando associada à atuação de corporações.

\section{Inventariando a produção sobre o tema}

As informações apresentadas neste item decorrem da consulta a duas bases de dados constituídas de publicações em Língua Inglesa e junto ao Banco de Tese da Coordenação de Aperfeiçoamento de Pessoal de Nível Superior, (Capes).

O levantamento relativo às publicações disponíveis para o período de 1990 a 2012 deu-se junto ao website Isi Web Knowledge (web-s) $)^{4}$ acessado pelo login da Capes, disponibilizado pela biblioteca central da Unicamp. A segunda fase do levantamento, relativa às publicações de 2013 a 2014, realizou-se pelo Web Science, site que deu continuidade a Web-S, por meio do link wokinfo.com acessado também com o login da Capes. ${ }^{5}$ 
Para localização dos textos em Língua Inglesa disponíveis nas bases selecionadas e eleição dos artigos adotou-se o descritor choice. A pesquisa realizada ateve-se à educação obrigatória, de modo que tal descritor foi relacionado aos termos elementary school e compulsory education. A busca por tais expressões se deu tanto pelo levantamento das palavras-chave quanto pela identificação de sua presença nos títulos dos trabalhos.

Os mesmos descritores e associações selecionados para pesquisa em publicações de Língua Inglesa foram utilizados na pesquisa sobre a produção nacional, neste caso referente à produção discente de teses e dissertações.

Fundos públicos, mercado privado e conservadorismo

A primeira fase da pesquisa no Web of Science permitiu 193 artigos relativos à educação básica, dos quais 46 foram excluídos pela ausência de resumo, condição exigida para a seleção mais rigorosa dos textos completos. Considerando os recortes e critérios adotados para caracterização das produções, excluíram-se do mapeamento 19 artigos, pois a escolha de escola por parte das famílias recebia tratamento secundarizado, uma vez que para seleção dos artigos eles precisavam indicar como objeto central as próprias políticas ou programas governamentais de "escolha", operacionalizados em distintos contextos. Chegou-se a um total de 66 artigos, dos quais apenas quatro versavam sobre educação domiciliar ou tutorias, como se verá na sequência (ADRIÃO, 2015).

De acordo com (ADRIÃO, 2015) no ISI/Web- no período de 1990-2014, o primeiro artigo localizado pelo descritor choice/escolha foi publicado em $1992 \mathrm{e} \mathrm{o} \mathrm{ano} \mathrm{de} \mathrm{maior}$ concentração de publicações foi 1996.

Destas produções, o campo empírico com maior número de trabalhos foram os EUA (12), seguidos da Inglaterra, especificamente, (8) e de reflexões sobre o Reino Unido (3). Cinco trabalhos não se referiram a um campo específico, pois dialogavam com a literatura (três revisões bibliográficas e dois diálogos com obras específicas) e seis produções referiram-se a estudos comparados. As demais 22 produções analisaram o tema em diversos países, conforme se depreende do gráfico 2 : 
Gráfico1. Campo empírico analisado por artigos disponíveis nas bases ISI e WEB of SCIENCE localizados pelo descritor CHOICE. Período 1990-2014.

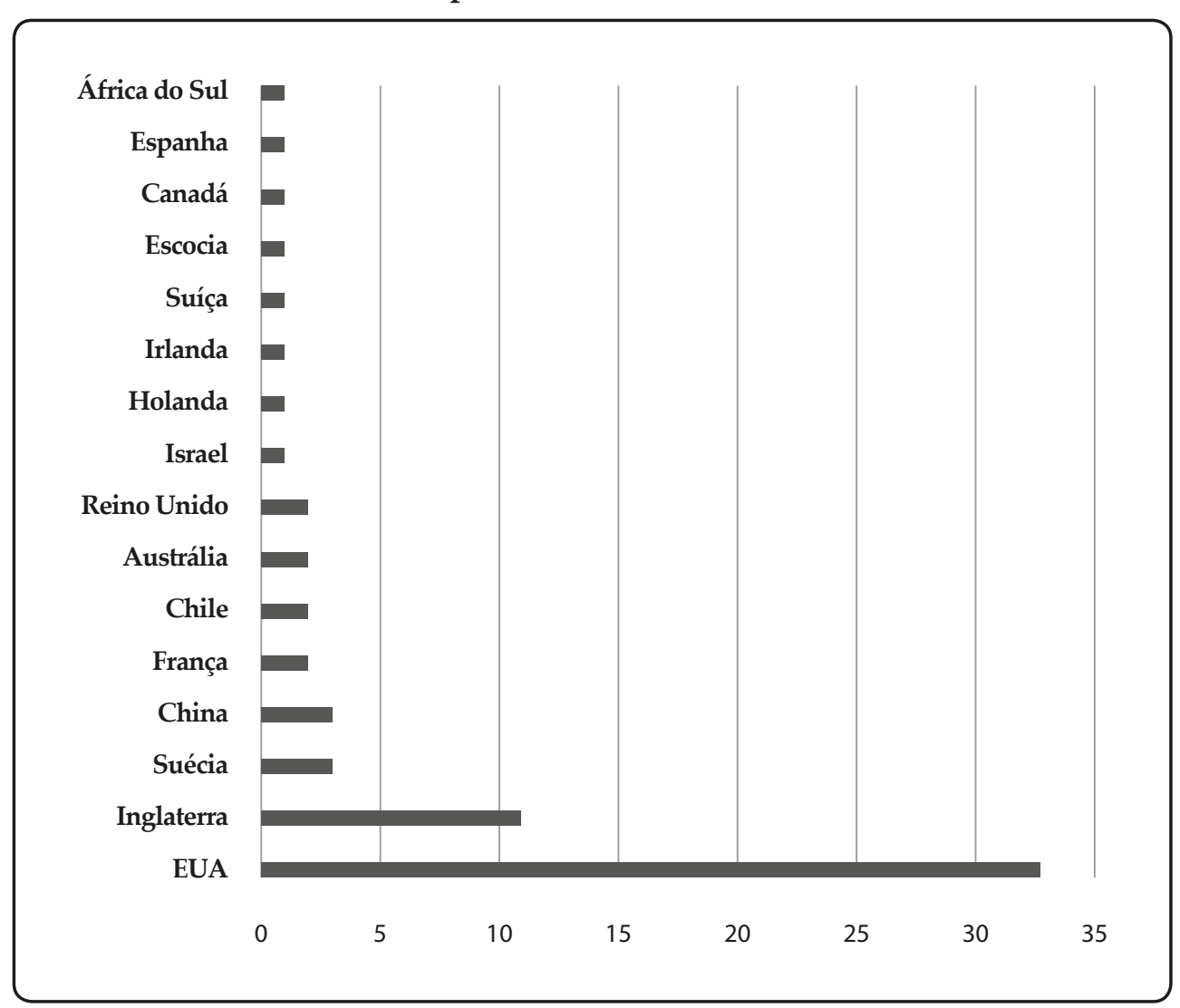

Fonte: ADRIÃO, 2015, p.92.

Entretanto, para este trabalho, dos 66 artigos relacionados a programas de escolha parental apenas quatro associavam esse descritor a programas ou políticas relativas à educação obrigatória, seleção decorrente da leitura de todos os resumos inicialmente identificados. O primeiro (AURINI; DAVIES, 2005), um estudo bibliográfico focalizando o Canadá, indica ser esta modalidade a forma mais radicalizada de oferta privada de educação. O segundo, analisando a implantação de experiências do tipo na Holanda, salienta a ampliação das desigualdades sociais e a negação do interesse das crianças (MERRY; KARSTEN; 2010). Os outros dois artigos se referem ao crescimento em países do Leste Europeu (SLOVA, 2010) e no Canadá (DAVIES, 2004) do que, no Brasil, denomina-se aulas particulares.

Já em relação às publicações nacionais, optou-se por inventariar a produção discente, para o que se acessou o Banco de Tese da Capes (mestrado e doutorado), o qual se encontrava disponível apenas para o período de 2011 a 2012, condição que exigiu a busca direta nos repositórios das universidades. Neste caso, selecionou-se uma universidade 
por região geográfica, levando em conta a inserção dos programas de pós- graduação expressa no número de matriculados. Além disso, considerou-se o conjunto das universidades estaduais paulistas. Em resumo, o mapeamento foi realizado por referência a oito universidades brasileiras: UFMG, UFRGS, UFPE, UNB, UFPA Unicamp, USP e Unesp. O total de 96 teses e dissertações, selecionadas por meio do mesmo descritor (agora em Língua Portuguesa) relacionados para a busca na Web-of Science (escolha) apenas três trabalhos relacionavam-se a políticas de escolha parental, dentre os quais, apenas dois tratavam de educação doméstica: Barbosa (2013) e Andrade (2014). Além disso, no período selecionado, nenhuma tese ou dissertação abordou com esta chave de análise a tutoria ou as aulas particulares.

\section{Sobre as produções encontradas}

Os artigos identificados na base internacional de dados e que associam a opção pela educação doméstica ou por aulas particulares a formas de privatização debruçaram-se sobre quatro campos empíricos: Canadá, Europa oriental, Ásia Central e Holanda.

Os textos que analisam o tema no Canadá são os mais antigos na base (2004 e 2005), publicados por Davies e Aurini. O texto School choice by default?, understanding the Demand for Private Tutoring in Canada, publicado pelo primeiro autor (2004), aborda o tema buscando analisar os perfis de pais que optam pela educação doméstica, também chamada pelo autor de tutoria. Considerando o Canadá como campo empírico, o autor pressupõe que esta opção responde a um setor de família para o qual o pagamento de mensalidade em escolas privadas não seria possível. Frisa, entretanto, a relação entre o crescimento desta forma de privatização com o crescimento das matrículas em escolas privadas: $20 \%$ na última década, sendo que em Ontário o aumento foi de $40 \%$, O texto informa que nesta província, entre 1991 a 2001, assistiu-se ao aumento de 44\% no número de escolas privadas. Para o autor, dois aspectos estimulam o aumento da tutoria: testes pós-ensino médio e o ranqueamento de universidades. Tais condições induzem famílias de menor renda a buscarem estratégias mais econômicas para o "preparo" de seus filhos.

Cria-se assim um novo mercado não composto por opções calcadas na religião, na elitização ou em aspectos ideológicos, elementos inicialmente indutores da não escolarização. O texto, resultado de pesquisa nacional, sugere que no Canadá a tutoria não é meramente um suplemento para dar aos filhos uma vantagem competitiva na escola pública, ao contrário, seria uma expressão de um maior desejo de uma alternativa educacional estratificada, dado que tutores diferem em custo, no tempo das aulas, nos material adotado etc.; exigências que "nivelariam" os clientes.

No ano seguinte, 2005, o artigo Choice without markets: homeschooling in the context of private education, de Aurini e do mesmo Davies, detém-se também na província canadense 
de Ontário, cujo crescimento das matrículas privadas foi percebido em artigo anterior. O texto parte do pressuposto que a educação doméstica é a forma mais expressiva do ensino privado e que tende a se expandir. Tomando Ontário como parâmetro, o artigo informa que, desde o início dos anos 2000, uma nova política provincial limita-se a considerar apenas a declaração dos pais de que as crianças recebem instrução satisfatória em casa para autorizar a não matrícula na escola. Tal lógica se estende da educação básica obrigatória à universidade e, para os autores, decorre da pressão de dois grupos: fundamentalistas religiosos e os contrários à escolarização obrigatória. Além disso, esta forma de privatização da oferta educativa ganha estímulo pela indústria de material didático. Por fim, o artigo frisa o perfil contraditório de seus demandantes, pois incluem, além dos acima assinalados, grupos de ativistas libertários contrários às políticas educativas hegemônicas competitivas e excludentes.

O terceiro texto, Private tutoring in Eastern Europe and Central Asia: policy choices and implications, de 2010 e autoria de Iveta Silova, toma como campo de estudos países da Europa Oriental e da Ásia Central que compuseram o chamado bloco socialista: Bósnia e Herzegovina, Croácia, Lituânia, Polônia e Eslováquia, Azerbaijão e Geórgia, Mongólia, Cazaquistão, Quirguistão, Tajiquistão e Ucrânia. Para a autora, a tutoria privada assume características específicas nas diversas regiões, entretanto tem em comum o aumento da motivação no aluno para aprender, ao oferecer aprendizagem inovadora e individualizada em comparação com os recursos das escolas regulares. Por outro lado, as tutorias/aulas particulares agravam as desigualdades educacionais, na medida em que poucos estudantes teriam acesso a estes mecanismos, situação acentuada na Ásia Central e Cáucaso.

Outro aspecto tratado no texto se refere à ampliação de um mercado privado de aulas particulares, pouco regulado pelos governos e que, por vezes, se assenta numa certa corrupção das próprias escolas regulares, quando se observa que são os docentes das aulas regulares que, paralelamente, ofertam serviços de tutorias.

Analisando a presença da educação doméstica na Holanda e considerando contradições decorrentes de sua ampliação, o texto de 2010, intitulado Restricted Liberty, Parental Choice and Homeschooling, escrito por Merry e Karsten, reflete sobre a ampliação das desigualdades sociais decorrentes da adoção do modelo, considerando que, mesmo setores libertários, admitem certa coerção do Estado com o fim de proteger os direitos de liberdade. No caso da educação, os autores indicam aumentar neste século XXI o controle do Estado holandês sobre a escolha das famílias, a quem, desde o final dos anos 1960, era facultada a matrícula na escola. Os autores destacam ainda que no país o sistema educativo é composto por escolas privadas subsidiadas pelo poder público.

Em relação à análise de produções discentes no Brasil, cujo objetivo era indicar se o tema integrou o rol de preocupações de pesquisadores em formação, localizaram-se apenas duas teses, ambas vinculadas à Feusp. 
A primeira, de 2013, defendida por Barbosa, intitula-se Ensino em casa: um desafio à escola? e tem por objetivo analisar a demanda por homeschooling no Brasil em um quadro de efetivação dos direitos à educação, não sendo foco do trabalho relacionar o fenômeno a processos de privatização.

O segundo trabalho, defendido em 2014, na mesma instituição, por Édison Prado de Andrade, intitula-se A educação familiar desescolarizada como um direito da criança e do adolescente: relevância, limites e possibilidades na ampliação do direito à educação, cujo objetivo é analisar os fundamentos da ampliação da demanda por "desescolarização", buscando ainda apresentar diretrizes para a regularização da educação doméstica no País. Também neste caso não há intencionalidade de relacionar a educação familiar desescolarizada, à privatização.

\section{Material didático como nicho de mercado: a Pearson PLC}

A Pearson PLC apresenta-se como liderança mundial em educação. Somente na chamada "hispanomérica", sua atuação ocorre em 20 países. De origem inglesa, com fundação datando do século XIX, o Grupo, proprietário do Finantial Times até 2015, cresceu, expandiu-se globalmente ao longo do século XX e desenvolveu inúmeros produtos e serviços para o campo educacional. Em sua página oficial, o Grupo Pearson informa que atua em 70 países, com um total de 35.000 funcionários e um grande número de empresas subsidiárias. Está listado na Bolsa de Valores de Londres (London Stock Exchange) e na bolsa de Valores de Nova Iorque (New York Stock Exchange). ${ }^{6}$

A apresentação das atividades da Pearson PLC, também designada como Grupo Pearson, deve-se não apenas ao fato de ser a corporação uma "gigante" mundial no mercado educacional (ROBERTSON, DALE, 2015; JUNEMAN, BALL, 2015), mas porque estudos anteriores identificam a presença crescente de suas atividades junto à educação pública brasileira, por meio da comercialização de sistemas privados e de ensino 7 e de tecnologias educacionais diversas. Tal inserção ampliou-se com a aquisição, em 2010, do controle acionário do Sistema Educacional Brasileiro (SEB), a partir de quando assume a produção e comercialização de sistemas privados de ensino para escolas privadas e públicas (ADRIÃO et al 2009, ADRIÃO 2009 e ADRIÃO et al. 2016).

No Brasil, o grupo figura entre os cinco maiores fornecedores desse conjunto de serviços, para o que conta com um setor específico, o Núcleo de Apoio aos Estados e Municípios (Name), adquirido em milionária negociação de compra por parte do Sistema Educacional Brasileiro (SEB).

Susan Robertson observa que, no contexto da globalização econômica, a incidência política de agentes privados no campo educacional, dentre os quais se encontra o Grupo Pearson, acentua-se a partir dos anos 2000 (ROBERTSON, 2012). Para a autora, 
o Grupo encontra-se entre os agentes globais mais proeminentes nas políticas educacionais (ROBERTSON, 2015).

Estudo desenvolvido por Juneman e Ball (2015) salienta que o Grupo Pearson passa por um processo de transformação que envolve não apenas esforço de crescimento no campo educacional, mas investimento adaptativo em direção a oportunidades de crescimento rápido.

Concordando com os autores, observa-se que a ampliação da Pearson PLC, por meio da incorporação de outras empresas e da extensão de sua atuação para novos mercados, operacionaliza-se pela distribuição de grande variedade de produtos e serviços na área de educação: livros didáticos; ambientes colaborativos de aprendizagem com uso de tecnologias; desenvolvimentos de testes de habilidades para organizações dos setores privado e público; material didático para ensino de Língua Inglesa; suporte para programas de cursos on-line; ensino superior; formação docente, entre outros. Segundo o próprio grupo, além de as operações ocorrerem em mais de 70 países conforme já mencionado, $65 \%$ das operações concentram-se nos EUA. ${ }^{8}$

Nos EUA, a Pearson oferece apoio ao ensino domiciliar as famílias que praticam o homeschooling, por meio da venda de material didático e de recursos on line, que disponibilizam informações e esclarecimentos sobre a modalidade e a legalidade do ensino domiciliar. ${ }^{9}$

Neste segmento, destaca-se o controle acionário, a partir de 2011, da TutorVista, empresa com atuação na Índia composta por uma rede de centros de treinamento de Língua Inglesa e, principalmente, pela comercialização de aulas particulares para mais de 10.000 estudantes ao redor do mundo por meio do acesso a plataforma disponível na internet. ${ }^{10}$

De acordo com a página institucional da empresa, a TutorVista comercializa assinaturas de aulas particulares on line, via conexão entre professores/tutores e alunos. Essa modalidade de oferta educativa é oferecida pela empresa a estudantes da Índia, Estados Unidos, Reino Unido, Austrália, China e Sudeste Asiático. Para tanto, conta com mais de 2.000 professores, que atuam como tutores. Além de tutoria on-line, a TutorVista também fornece ajuda para a realização de lição de casa, aulas particulares suplementares e assistência especializada para testes e exames. ${ }^{11}$

No Brasil, além de comercializar sistemas privados de ensino para redes públicas e privadas, por meio de sua editora, o Grupo participa do Programa Nacional do Livro Didático (PNLD), iniciativa do governo federal que financia livros didáticos para estudantes de escolas públicas em todo o território nacional (ADRIÃO, et al, 2015).

Os negócios relativos ao ensino domiciliar não constam da cartela de produtos oferecidos em território brasileiro. Entretanto, nos Estados Unidos o grupo mantém uma página específica para venda de materiais didáticos para todo período da educação escolar regular norte-americana até o 12ํㅡ. Grau. Há também recursos virtuais disponíveis, 
tais como orientações digitais para ensino de conteúdos específicos, alguns planos de ensino e acesso a blog sobre temas de interesse das famílias. A página ainda oferece informações sobre a legislação relativa ao ensino domiciliar no país. Tais informações apresentam normativas e mecanismos de regulação sobre esse modelo de oferta educacional em vigência em cada um dos estados americanos.

Para realizar as compras de materiais é preciso que as famílias inscrevam-se na página, como ocorre em vendas e-comerce. Todavia, foi possível acessar informações sobre os custos de materiais para ensino de Ciências da pré-escola o oitavo grau. Os preços variam entre US\$ 61,97 e US\$ 63,97 por material. Por meio de consulta a lojas on-line de livros didáticos equivalentes nos Estados Unidos, o custo dos livros disponíveis por outras editoras pode chegar a um terço dos valores anunciados do Grupo Pearson.

\section{Considerações finais}

A caracterização do Grupo Pearson e de sua presença na comercialização de produtos voltados para o ensino domiciliar e as aulas particulares/tutorias demonstra a subordinação dessas modalidades de oferta educativa aos interesses mercantis. A literatura que associa essas práticas educativas a formas de privatização analisa contextos nacionais nos quais a legalização do ensino domiciliar apresenta-se se como exercício de escolha parental. Localiza-se nesses estudos, a fragilidade na regulação do mercado voltado ao atendimento de demandas produzidas por tais práticas, o qual recebe estímulo adicional pela ampliação de ferramentas de educação a distância.

Já a prática das aulas particulares ou tutorias, amplamente disseminada no Brasil, carece ainda mais de regulação. Na medida em que se apresenta como complementação aos estudos escolares e não sua substituição, as empresas voltadas para as aulas particulares crescem na mesma proporção que se estratificam os sistemas escolares. No Brasil, o grupo Tutores ${ }^{12}$ possui 77 franquias físicas distribuídas pelo País. Tem-se, assim, um promissor campo de negócios para corporações que atuam em âmbito global.

Implodindo os pressupostos de maior liberdade e de acesso mais democratizado ao conhecimento que têm alicerçado em parte a ampliação de formatos individualizados de acesso à educação domiciliar (BARBOSA, 2016), a "profissionalização" do atendimento a este formato educacional por empresas explicita um processo duplicado de privatização. Em primeiro lugar porque, como já assinalado por Apple (2003), a educação domiciliar nega a regulação estatal e a possibilidade de que os sistemas escolares atuem, mesmo que limitada e contraditoriamente, como mecanismo de diminuição de desigualdades e segregação. Barbosa (2016) recupera a crítica sobre esta opção de educação na América do Norte a qual se centra na conotação "privada" dos percursos formativos das novas 
gerações, em detrimento de um desenho de inserção educativa socialmente construído e representado por um aparato escolar.

Em segundo lugar, a efetivação desse tipo de educação por corporações estratifica o acesso a conteúdos e práticas educativas em função da renda das famílias, reservando a elas e aos educandos a condição de consumidores e não de sujeitos de direitos. Objetivamente, se consideramos para a análise os custos relativos à aquisição de materiais e serviços comercializados, por exemplo, pelo Grupo Pearson, e o incentivo a políticas de escolha parental nos EUA, o aceno, por parte do atual presidente Donald Trump, para que haja financiamento público à prática do homeschooling não surpreende e consubstanciaria um terceiro aspecto da privatização da educação: a destinação de fundos públicos para a oferta privada. ${ }^{13}$

Pressupondo que numa economia capitalista a expansão dos interesses do capital encontra limites apenas e quando da presença de mecanismos de controle e regulação forjados pela resistência à sua reprodução, alerta-se para as consequências que o aprofundamento do acesso desigual ao conhecimento, como decorrência da ampliação de uma educação "delivery", pode trazer para a efetivação do direito humano à educação.

Recebido em 20/08/2017 e aprovado em 15/11/2017

\section{Notas}

1 A Associação foi criada em 1983 por dois pais adeptos da educação doméstica e advogados, com o objetivo de atuar na promoção do direito a esta opção familiar. Disponível em. https://www.hslda.org/about. Acesso em 10 de junho de 2017.

2 Disponível em https://www.hslda.org/laws/. Acesso em 10 de dezembro de 2016

3 Conforme https://www.responsiblehomeschooling.org/public-funding-for-homeschooling-must-come-with-accountability/. Acesso 24/06/2017.

4 Link de acesso: http://apps.webokbowledge.com/UA_GeneralSearch_imput.do?

5 As informações constantes nas duas fases do Banco de Dados diferenciaram-se entre 1990 e 2012, uma vez que para esta base o resumo dos trabalhos não era uma exigência, o que na fase seguinte (2013-2014) passou a ser regra.

6 A Pearson PLC é um grupo de capital aberto que originariamente atuava no campo da mídia impressa. Ao longo do século XX foi expandindo seu capital para a educação. O grupo tem por slogan o tema " Pearson, líder em Educação no Mundo"( https://br.pearson.com.Acesso em 10 de janeiro de 2017). No Brasil, em 2013, o grupo já fora anunciado como liderança no ramo de escolas de inglês. (http://www2.valor.com.br/ empresas/3361408/pearson-compra-multi-por-r-195-bi-e-lidera-setor.Acesso em 16 de janeiro de 2017).

7 O sistema privado de ensino constitui-se por cesta "integrada por atividades tradicionalmente desenvolvidas pelas equipes pedagógicas dos órgãos da administração pública e das escolas: formação continuada de educadores, acompanhamento e supervisão das atividades docentes; investimento na produção e dis- 
tribuição de materiais didáticos aos alunos; processos de avaliação externa e interna, entre as principais encontradas (ADRIÃO et al., 2009, p. 806).

8 PEARSON, 2016. Disponível em:https://www.pearson.com/corporate/investors.html.Acesso em 10 de junho de 2017

9 http://www.pearsonhomeschool.com

10 http://timeline.pearson.com/. Acesso em 27/06/2017

11 http://www.tutorvista.com/corporate.php. Acesso em 28 /06/2017

12 https://www.tutores.com.br/unidades.asp\#conteudo. Acesso em 16/07/2017

13 Durante sua Campanha presidencial Donald Trump anunciou que dentre as proposições a serem encaminhadas ao Congresso Nacional nos primeiros cem dias de seu futuro mandato, incluía-se o apoio financeiro às famílias para que escolhessem a educação a ser ministrada a seus filhos, condição que incluía a educação doméstica. (http://www.npr.org, 9/11/2016)

\section{Referências}

ADRIÃO, Theresa (coord.). Estratégias municipais para a oferta da educação básica: as parcerias público-privadas. Relatório de pesquisa: Fapesp, 2009.

. Dimensões da privatização da educação básica no Brasil a partir de 1990: Um diálogo com a produção acadêmica. 2015.

Tese (Livre Docência). Faculdade de Educação. Universidade Estadual de Campinas. Unicamp. Campinas, 2015.

ADRIÃO, Theresa; et al. Privates Systems of Education in brazilian public education: consequences of commodification for the rigth to education, 2015.

Grupos empresariais na educação básica pública brasileira: limites à efetivação do direito à educação. Educação \& Sociedade, v. 37, p. 113-131, 2016.

. Uma modalidade peculiar de privatização da educação pública: a aquisição de "sistemas de ensino" por municípios paulistas. Educação \& Sociedade, v. 30, n. 108, p.799-818, 2009.

APPLE, Michael Reestruturação Educativa e Curricular e as Agendas Neoliberal e Neoconservadora: Entrevista com Michael Apple. Currículo sem Fronteiras, v.1, n.1, pp.5-33, Jan/Jun, 2001.

AURINI, Janice; DAVIES, Scotr. Choice without markets: home schooling in context of private education. British Journal of Sociology of Education. v. 26, n. 4, set, p. 461-474, 2005.

BALL, Stephen J. Performatividade, privatização e pós-Estado do Bem-Estar. Educação e Sociedade, Campinas, v.25, n.89, pp.1105-1126, set./dez., 2004.

BARBOSA, Luciane. Ensino em casa no Brasil: um desafio à escola? Tese (doutorado em educação). Faculdade de educação, Universidade de São Paulo, São Paulo, 2013.

BARBOSA, Luciane. Homeschooling no Brasil: ampliação do direito à educação ou via de privatização? Educação e sociedade, v. 37, pp.153-168, 2016.

COSTA, Jorge Adelino; NETO-MENDES, Antonio; VENTURA, Alexandre. Explica: investigação sobre o mercado das explicações. Aveiro, Universidade de Aveiro, 2009. 
DAVIES, Scott. School choice by default? Understanding the demand for private tutoring in Canada. America Journal Education. V. 11, n. 3, 235-255, 2004.

HILL, Dave O. O neoliberalismo global, a resistência e a deformação da educação Currículo sem Fronteiras, v. 3, n. 2, pp. 24-59, Jul/Dez, 2003.

JUNEMAN, Carolina; BALL, Stephen J. Pearson and palf The Mutating Giant. Retirado em 10 de janeiro de 2017. 2005. Disponível em https://www.ei-ie-al.org/mercantilizacion/ Mercantilizaci\%C3\%B3n\%20educativa-\%20art\%C3\%ADculos,\%20publicaciones/Ingl\%C3\%A9s/ Junemann $\% 20$ C $\% 20$ and $\% 20$ Ball $\% 20$ S. $\% 20$ (2015)\%20Pearson\%20and\%20PALF, $\% 20$ The $\% 20$ Mutating\%20Giant.\%20pdf.pdf $>$.Acesso em 28 de maio de 2017.

LEVIN, Henry (ed.). Privatzing Educaction. Can the marketplace deliver choice, efficiency, equity and social cohesion? Westview Press: Cambridge, 2001.

MERRY, Michael S.; KARSTEN, Sjoerd. Restricted Liberty, Parental Choice and Homeschooling. Journal of Philosophy of Education. V. 4, 497-514, 2010.

PRADO, Édison. A educação familiar desescolarizada como um direito da criança e do adolescente: relevância, limites e possibilidades na ampliação do direito à educação. Tese (Doutorado em Educação). Faculdade de Educação, Universidade de São Paulo, São Paulo, 2014.

ROBERTSON, Susan; DALE, Roger. Comparing Policies in a Globalising World: Methodological Reflections. In: HADJAR, Andreas; GROSS, Christiane (eds.). Education Systems and Inequalities, Bristol: Policy Press, 2015.

ROBERTSON, S.; DALE, R. Comparing Policies in a Globalising World: Methodological Reflections, 2015.

SLOVA, Iveta. Private Tutoring in Eastern Europe and Central Asia: Policy Choices and Implications. Compare: A Journal of Comparative and International Education, v. 40, n. 3, 327- 344, 2010.

\section{Sites Consultados}

https://www.pearson.com/about-pearson/who-we-are.html

https://www.pearson.com/investors/managing-your-shares.html

https://www.pearson.com/products-and-services.html

https://www.nyse.com/quote/XNYS:PSO

http://www.londonstockexchange.com/exchange/prices-and-markets/stocks/summary/companysummary/GB0006776081GBGBXSET1.html

https://www.pearsoneducacion.net/

https://www.hslda.org

http://www.npr.org/2016/11/09/501451368/here-is-what-donald-trump-wants-to-do-in-his-first-100days 